\title{
The Insiders' Perspectives: A Focus Group Study on Gender Issues in a Computer-Supported Collaborative Learning Environment
}

\author{
Minh Q. Huynh \\ Southeastern Louisiana \\ University, Hammond, \\ LA, USA
}

\author{
Jae-Nam Lee \\ Kookmin University, \\ Seoul, Korea
}

\author{
Barbara A. Schuldt \\ Southeastern \\ Louisiana University \\ Hammond, LA, USA
}

\section{Minh.Huynh@selu.edu}

\section{isjnlee@kookmin.ac.kr}

bschuldt@selu.edu

\section{Executive Summary}

There is little doubt that the advent of collaborative technologies in recent years has brought some significant changes in the way students learn, communicate, and interact with one another. In recent years, this emergence has sparked increased interest for research into the role and impact of instructional technologies on group learning. Despite the widespread use of different instructional technologies to support teaching and learning in today's classroom, our understanding of these technologies and their underlying impacts on learners and instructors remains fragmented, specifically with regard to gender learning issues. One important area that has been neglected in the research is the impact of classroom technology on gender classroom equity and learning processes. Indeed, only a few studies have examined the gender learning issues inside the group learning process as it naturally occurs in an actual classroom. How do female students, as well as their instructors, perceive gender issues in their classroom? What are the experiences of female students in an online learning environment? Do technologies contribute to or hinder the achievement of gender classroom equity and positive learning experiences? These are some of the interesting but complex questions that this study attempted to explore.

This paper presents a focus group study on the perspective and experiences of female management students and their instructors in an online learning environment that used a computer supported collaborative learning (CSCL) system to facilitate student-to-student interactions. To explore the potential impact of a CSCL system on gender classroom equity, an interpretive field study was conducted to glean insights about the insider participants' experiences and perceptions. This study focused on both the female students and their instructors regarding their perceptions and experiences with the use of CSCL and their learning processes. Our research sites involved two graduate courses that used the computer supported collaborative learning in place of face-toface discussions at least part of the semester. Drawn from the field notes and the transcripts of the

Material published as part of this journal, either on-line or in print, is copyrighted by the publisher of the Journal of Information Technology Education. Permission to make digital or paper copy of part or all of these works for personal or classroom use is granted without fee provided that the copies are not made or distributed for profit or commercial advantage AND that copies 1) bear this notice in full and 2) give the full citation on the first page. It is permissible to abstract these works so long as credit is given. To copy in all other cases or to republish or to post on a server or to redistribute to lists requires specific permission and payment of a fee. Contact Editor@JITE.org to request redistribution permission. interviews taken at the end of the semester, findings are reported along with an interpretation of the results. By virtue of being involved in and close to the phenomenon, subtle aspects on gender equity issues were detected from the use of the CSCL. The study is also among the first empirical research that applies and extends the view of e-learning produc- 
tivity from the perspective of Habermas' Cognitive Interests Theory (Huynh, 2005). What emerged from this exploratory investigation is a deeper understanding of CSCL learning processes with respect to the gender issue. Such understanding leads to the practical implications as well as more definitive guidance for the direction of future research on the topic of gender issues in an online learning environment.

Keywords: Focus study, Instructional technologies, Distance education, Computer supported collaborative learning, Gender classroom equity, Gender bias, Feminist perspective, Critical social theory.

\section{Introduction}

There is little doubt that the advent of collaborative technologies in recent years has brought some significant changes in the way students learn, communicate, and interact with one another. The deployment of computer supported collaborative learning (CSCL) is a good example of how collaborative technologies can be used to facilitate and enhance group learning and interaction (Alavi, 1994; Alavi, Wheeler, \& Valacich, 1995; Briggs, Ramesh, Romano, \& Latimer, 1995; Kwok, Ma, \& Vogel, 2002). Despite our need to assess the impact of these technologies in education, the research still lags behind the adoption of collaborative technologies in practice. As Alavi and Leidner (2001) put it, there is a fundamental need to understand how the use of these technologies can improve the learning process. Indeed, our understanding of these technologies and their underlying impacts on learners and instructors remains fragmented. One important area that has been neglected in the research is the impact of classroom technology on gender classroom equity and learning processes. A glimpse of the relevant literature reveals that only a few studies have looked at the gender issues in a computer-mediated learning environment (DavidsonShivers, Morris, \& Sriwongkol, 2001, 2003; Larson, 2002; Wang \& Sierra, 2002; Young \& McSporran, 2001), despite the deep penetration of technology being deployed in classroom and the significant increase in the number of female computer users (Iankelevich, 2005; Ono, 2002).

The field study described in the following pages was designed to explore learning and gender issues from an insider's perspective. The scope of this study is to look at the learning process within the implementation of a CSCL environment and document the perception and experiences of those who took part in the process. More specifically, the focus is on understanding issues related to the differences between male and female behaviors as well as the role and impact of technologies on gender classroom equity and learning experiences. In a broader context, this study conveys the importance and relevance of gender issues in today's technology-rich environment. To achieve the objective, focus group interviews were conducted to solicit insights from the participants in actual classes. The findings from these interviews and field observations are reported. The results of this exploratory study provide useful implications by recognizing a deeper understanding of both what female students experience, and the role of technology in group learning processes. This will be of value to academics and practitioners who use online learning environments.

The paper is organized into eight sections. Following the introduction is a characterization of CSCL and the environment it supports. Section three highlights some of the gender issues relevant to CSCL environment, which motivated this study. Section four presents conceptual underpinnings derived from Habermas' Theory of Cognitive Interests (Habermas, 1972; Huynh, 2005). Section five describes the field study. Section six reports the analysis and results from the field study, while the section seven discusses the implications for research and practice and the directions of future research. The last section summarizes the study's contributions. 


\section{Computer Supported Collaborative Learning}

For the purpose of this study, we characterized CSCL as an integration of information technology (IT) into the course design and teaching strategy to support collaborative learning approaches. Two key elements in this definition are the use of collaborative learning and the integration of IT to facilitate group work in the classroom. Collaborative learning in general refers to a pedagogical approach that allows students to work together in a small group. The intention is to create an environment where every student can participate in and contribute to an assigned task. The integration of IT simply refers to the adaptation and use of appropriate groupware to mediate and support collaborative learning activities inside and outside of the classroom. Thus, a CSCL environment could be considered a blended learning environment that involves group interactions, both online in a computer-mediated mode and face-to-face in a classroom setting. The goal of CSCL is not only to improve knowledge acquisition but also to facilitate shared understanding in knowledge construction and to overcome both internal and external constraints.

This study looked specifically at the learning process within the implementation of a CSCL environment. The primary objective was to explore potential impacts that CSCL has on the groups' learning processes, in particular those that are related to gender equity. In addition, the study explored any indicators of potential mechanisms that may support the use of computer-based technologies as an empowering tool for students' learning processes.

\section{Gender Issues in a CSCL Environment}

To understand why gender issues in the learning process are important, studies related to gender were reviewed. The purpose is not to present a review of the vast body of research literature in the area of gender classroom equity, but to simply establish the relevance of this study within the larger context of gender research literature. As a result, this literature review is limited. According to Wyatt (1993), "one of the basic feminist precepts derives from the observation that gender, class, and race constitute major bases for social organization. The experiences of people of different genders, classes, and races vary widely within most cultures." In their review on leadership and gender, Shimanoff and Jenkins (1994) noted that both women and men could be effective leaders, but that men are more often perceived to be leaders than are women. Stereotypes have led to the perception that women are less able to lead than men. Pearson, West and Turner (1994, p.94) in their own review reported that women tend to be less informative, objective, and goaloriented than men. Consequently, women are sometimes perceived to be less competent in problem-solving or decision-making situations. On the positive side, Pearson et al. (1994, p.96-97) cited research from the 1970s indicating that women are more cooperative and willing to share resources. They are more interested in fair outcomes and the continued relationship rather than in competition and winning. While men are more likely to engage in aggression, women are more likely to use socially acceptable behavior to resolve conflict. According to Herring (2001), the Internet rather than being a gender neutralizer allows typically female communications styles to be used, therefore, identifying the sender as a female. In addition, many women reveal their gender even in environments where it would be to their advantage to remain anonymous.

Furthermore, Wilson (2004) proposes that the use of technology and computers is predominately thought of as a male domain. It was theorized that by using computer-mediated communication such as CSCL systems, all traces of information regarding gender, race, social class, etc. would make the interactions autonomous (Herring, 2000). Gender would not be a factor in the interactions. Yet, according to Herring (2000) there is the predisposition for Internet users to exhibit culturally-learned gender styles in their interactions. So, even though the technology does not specify gender, the individual user, either consciously or unconsciously, inserts into his/her interactions gender attributes. Such a predisposition in effect creates a barrier for female participants, 
especially in an online classroom environment, where instructors want students to be anonymous and equal. It means that there exist gaps between male and female students' perception and experience in today's classroom environment. Indeed, a number of past studies have shown that female students' interaction patterns and learning attitudes differed from their male counterparts (Gunn, McSporran, Macleod, \& French, 2003; King, 2000; Larson, 2002; Wang \& Sierra, 2002).

However, deeply rooted gender biases exist in today's classroom. From their extensive study of small group communication, Hall and Sandler (1982) revealed the gender biases that existed in their communication classes and documented many ways in which women's contributions and participation were routinely excluded or devalued. Their findings provided some controversial evidence on how gender biases of both male and female instructors, as well as male students, affected the social interactions and women's performance in classrooms. Based on Hall and Sandler's study cited above, as well as from other studies (Gilligan, 1982; Hensel, 1991; Pearson, West, \& Turner, 1994; Shimanoff \& Jenkins, 1994) on gender issues in general, these researchers infer that there are gender biases and stereotypes regarding female students in today's traditional classroom.

The research pointed to unanswered questions, such as: How do female students, as well as their instructors, perceive the gender issues in their classroom? Is there a difference in a male mode of behavior versus that of a female? How do female students perceive their experience in an online learning environment? Do technologies contribute to or hinder the achievement of gender classroom equity and positive learning experience? What role do technologies play or what impact do they have in the learning process? These are some of the interesting but complex questions that lead to this study. While it was not feasible to answer all these questions, the goal was to document and report what was observed and learned from this field study. The insights are based on the perspective of those insiders who took part in the actual learning processes. In a broader context, this study conveys the importance and relevance of gender issues in today's technology-rich environment.

\section{Conceptual Underpinnings}

In order to make sense of what is actually going on in the field and what is conveyed from the data, we need some point of reference through which to interpret the meaning of the observed phenomenon. Therefore, a conceptual base was needed to guide this field study, as well as, the data analysis and interpretation. Although there are a number of social theories and philosophies, among the most cited ones in information systems (IS) literature are Gidden's Structuration Theory, Foucault's work on Power and Knowledge, and perhaps Habermas' Critical Social Theory (CST) (Mingers \& Willcocks, 2004). For instance, specifically related to feminist work is the study by Hellens and her associates (2004), in which they explored dualisms in female perceptions of IT work using Gidden's Structuration Theory. Similarly, Brooke (2002) made the case of how Foucault's work can be applied to advance the topics of emancipation and power relations in IT research. Brooke's article provides a good conceptual foundation for adoption of Foucault's work in the research of not only IT in general, but also IT gender related studies. This is because Foucault's work addresses the fundamental issues involving power and knowledge. Finally, according to Jones (2000), the concept of CST, associated with Jurgen Habermas, is probably second to Giddens in citations in IS research literature (for more details about Habermas's CST and its implications for IS research, see Mingers \& Willcocks 2004, chapter 6). Yet, there are few studies with the application of CST in the area of IT impacts on gender issues. Hence, this was additional motivation for adapting Habermas' CST as the conceptual point of reference in this study.

Habermas's work is very broad and abstract. For the purpose of this study, references were limited mainly to his work on Cognitive Interests Theory (CIT). The CIT was used to frame and un- 
derstand the complexity of gender classroom equity and learning process. CIT was selected because it provided a context in which to encompass various interests, diverse perspectives, and even value conflicts. All of these, according to Habermas, are associated with specific conditions of the social, historical, and technological setting at a certain time. In the context of this study, concerns such as the presence and absence of participation, equal access, open communication, critical reflection, and emancipatory practices are, though subtle and often hidden, relevant and essential factors for the understanding of gender classroom equity and learning issues in an online learning environment.

\section{Adaptation of Habermas' Theory of Cognitive Interests}

In his Theory of Cognitive Interests, Habermas introduces three distinct orientations that he called instrumental, communicative, and emancipatory. These orientations are drawn from his ideas of the relationship between knowledge and human interests. In this study, these three orientations are adapted to provide a framework in which to distinguish three different kinds of learning processes as: instrumentally-oriented, communicatively-oriented, and emancipatory-oriented.

The instrumental orientation is driven by the technical interest that basically refers to the interest of human beings in acquiring knowledge that will facilitate their technical control over natural objects (Habermas, 1972). It concerns the ways individuals learn to control, manage, and manipulate the environment to achieve his/her goals. In an online learning environment, the instrumental orientation stresses drive for the efficiency and effectiveness. The use of technology is intended for the facilitation of a flexible learning environment. Its purpose is primarily to provide students the opportunity to learn in their own time frames, at their own pace, and at any physical location (Huynh, 2005).

The communicative orientation is derived from practical interest. According to Habermas (1972), practical interest is basically the interest in understanding and making sense of conditions for meaningful communication and dialogue. It generates knowledge in the form of interpretive understanding, which can inform and guide practical judgment. The communicative orientation is manifested through the shared understanding, positive socialization, and consensus building among learners. Stressed are social interactions through sense making, which is a process of communicating and negotiating for shared understanding and consensus. The goal of communication orientation is to encourage learners to seek shared understanding, be receptive to alternative perspectives, negotiate points of view, and care for both individuals and the group as a whole (Cranton, 1996). For online learning environments, the communicative domain focuses on communication that involves students understanding, describing, and explaining not just their ideas, but also their intentions, values, beliefs, feelings, and attitudes toward one another. Such communication is presumably shaped by linguistic codes, classroom norms, school culture, and societal expectations. The use of technology supports an environment that facilitates shared understanding and enhances group communications (Huynh, 2005).

The emancipatory orientation reflects the desire to be liberated from unwarranted constraints. Habermas (1972) ascribes this third kind of interest as the emancipatory interest. It refers to a basic human interest in rational autonomy, freedom from constraints, and removal of distortions. This emancipatory interest is manifested through personal transformation as a result of overcoming internal and external constraints. This is based on premise that people are capable of achieving freedom from self-imposed constraints, conditions of distorted communication, and environmental constraints (Roderick, 1986). For an online learning environment, the emancipatoryoriented learning domain focuses on critical reflection. The knowledge gained through critical reflection helps an individual to understand how his/her past influences his/her current state (Mezirow, 1981, p.5). The process of inquiry through critical reflection encourages an individual to challenge his or her taken-for-granted assumptions, to engage in an open discourse of accepted 
values and practices, to seek out new perspectives, and to work toward changes eliminating or minimizing concerns (Cranton, 1996, p. 30). Changes in attitudes, beliefs, interpretation, and concepts that give rise to new ones are considered the outcomes of emancipatory learning. The use of technology is mainly for the purpose of fostering an environment that promotes equal participation, open communication, and diverse perspectives (Huynh, 2005).

\section{Field Study}

\section{The Field Study Method}

The method used in this study was focus group interviews. These group interviews served two purposes. The first was to gain direct feedback from both the instructors and the students about their experiences with the CSCL and their perception on broad gender issues in classroom. The second purpose used the group interview as a way to capture observations in the "field" regarding emerging issues from the participants' own perspective. The intention was directed toward understanding specifically how female students and their instructors view and perceive the CSCL environment compared with similar activities in a face-to-face classroom. The target subjects were female students because, at the time, the thought was that forming a focus group with only female students to discuss gender related issues would allow more free flowing and open expression without the presence of their male counterparts. In addition, the male instructors for both courses were interviewed about their perceptions of gender equity in their classroom and the use of the CSCL.

\section{The Research Site}

The study was conducted with students and instructors from two graduate-level elective courses at a major university located in the Northeastern part of the United States. The two courses will be referred to as 'M5' and 'H5' for the sake of brevity. 'M5' was an MIS strategy course that emphasized the interrelationships among IT applications, management and organizational structure and processes. There were a total of nine students enrolled in this particular class - three females and six males. 'H5' was "Leadership in Organizations" a human resource management course. The main objective of $\mathrm{H} 5$ was to help students experience and gain insights into the emergence and development of leadership. There were 18 students in this class - nine females and nine males.

These two classes were chosen for this study for two reasons: One, the instructors used the GSS application TeamWave version 2.2, to support dispersed group interaction; and two, the instructors were willing to experiment with the use of TeamWave and were supportive of this field study. The participation in the study was voluntary. All participants signed a consent form, which was reviewed and approved by the Human Subjects Committee at the university.

At the beginning of the first class meeting, the researcher informed all students about the research project and explained the reasons for participating in the study to these two specific classes. Afterward, the researcher attended classes regularly and was gradually perceived and treated like any other member of class. The field study with these two specific classes lasted over 15 weeks. The data were collected from four primary sources: electronic communication records, videotapes of the classroom discussion sessions, focus group interviews, and field notes from the events observed. Because the scope of this study was on gender issues, the data analysis and interpretation focused mainly on the transcripts from the focus group interviews. When necessary, insights about the data were drawn from other sources and noted in the analysis section. 


\section{Technology Used}

TeamWave is promoted as the electronic equivalent of a meeting room, offering a variety of tools including Brainstormer, Whiteboard, Message Board, PostIt, Idea Organizer, etc. (see Figure 1). The purpose of using TeamWave was to provide students a virtual space to conduct group work and engage themselves in a group discussion whenever and wherever without relying on a faceto-face meeting. The advantage of TeamWave is it offered a great variety of useful tools designed to support group work and group interaction over the Internet. A group can use these tools to make a decision or to brainstorm for ideas. The Brainstormer, the Chat, the Whiteboard, the Message Board, and the Postlt were among the tools that our subjects used to facilitate and coordinate their group work online. From the Internet, they could sign on to TeamWave from anyplace and at anytime. This provided groups added flexibility to engage in various online activities without meeting together in person.

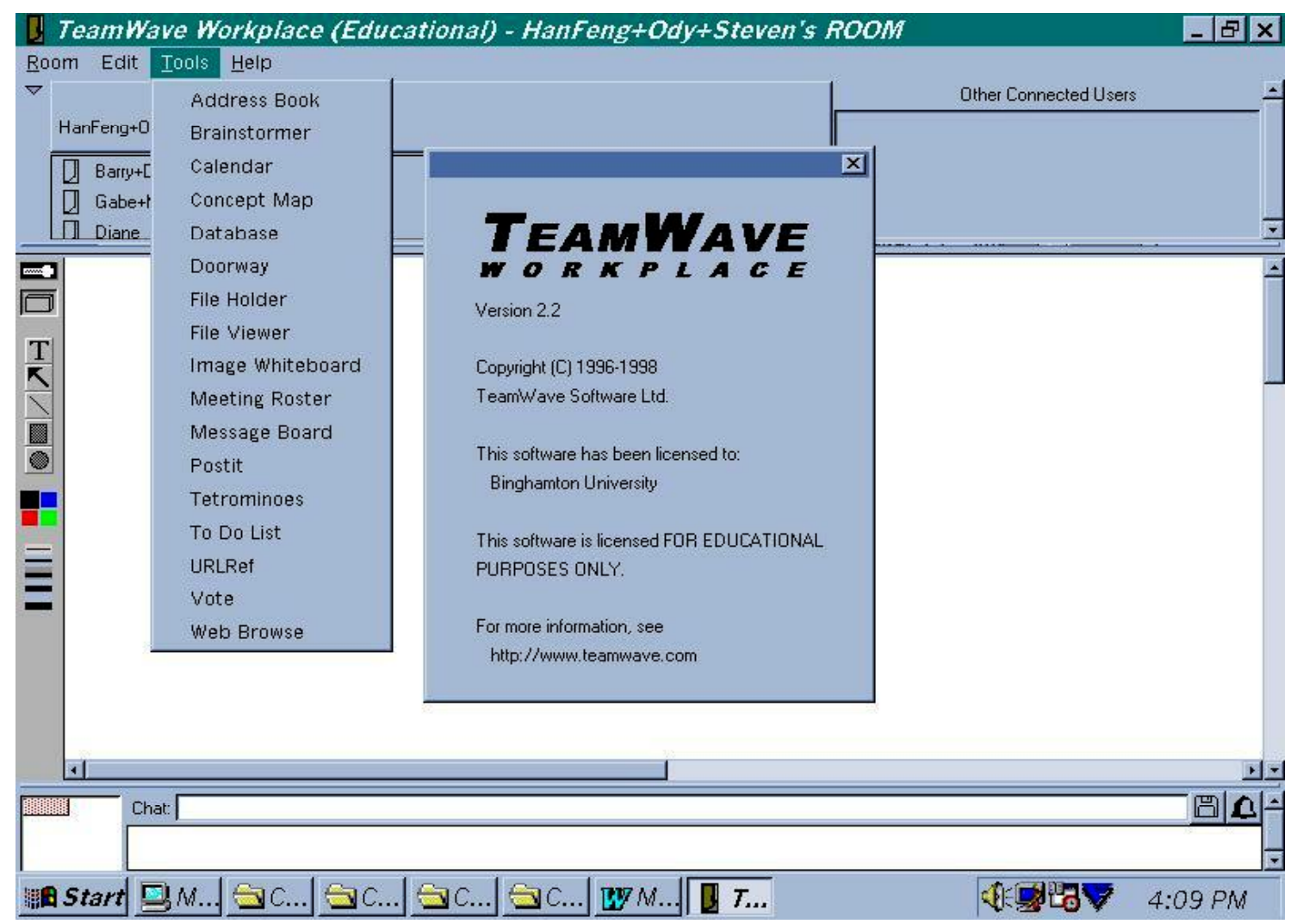

Figure 1: TeamWave Workplace Initial Screen with Pull Down Menu of Feature

\section{The Learning Tasks}

\section{Group discussion in H5 class}

The online case discussions were conducted once a week outside of class time. These online sessions usually lasted no longer than one hour. In these sessions, students would log on from various locations, e.g. from work, home, or school lab. A week prior to the discussion, the instructor assigned a specific case to students. Students were expected to read and come prepared for the online discussion.

Three specific tools - Chat, Brainstormer and PostIt - of TeamWave: were used extensively in the H5 online case discussion sessions. In a Chat window, participants could type their comments or have a textual conference with others. Similar to the Chat, the Brainstormer also served as a place 
for participants to contribute their comments except that their names were not automatically displayed. The PostIt worked as a blackboard where a facilitator could use it to facilitate the discussion.

\section{Group discussion in M5 class}

All the case discussions in M5 took place in the last five weeks of the semester. There were a total of seven cases assigned. The first five cases were analyzed in a face-to-face configuration of a traditional classroom while the last two cases were analyzed and discussed online using TeamWave. The format of the case discussion was highly structured in M5 class. The instructor asked students to analyze the cases using a "rich picture" framework around the following seven aspects:

(1) Actors: who is involved in the case?

(2) Plot: What are the driving issues in the case?

(3) Narrative: What happened in the case?

(4) Moral of the story: What lessons are learned?

(5) Relationship to the current chapter in the textbook;

(6) Relationship to other chapters in the textbook;

(7) Relationship to the group project.

These online sessions were held outside of class. Again, students logged on from various locations and the interaction took place in real time. The Chat and Postlt tools in TeamWave were used to conduct the case analysis based on the "rich picture" approach. The Chat tool provided the students a space to type comments and raise issues. It also allowed the instructor to intervene and offer his opinions. The PostIt tool provided students with a way to organize their ideas by cutting and pasting text from the Chat. It was also used for the instructor to guide the discussion.

\section{Field Study Analysis and Results}

\section{Perceived Gender Stereotypes}

As mentioned earlier, part of the fieldwork involved a series of interviews with instructors and students at the research sites. Since all of the interviewees were from the school of management, the first question asked was whether they perceived business education, in general, as genderneutral or not? All of the female students except one viewed business education as genderneutral. They did not see any gender bias. The student who disagreed with this insisted that the school of management faculty in general still focus more on "HE" than "SHE," although she believed that people are beginning to recognize this male bias at last.

The M5 instructor expressed, "...I am sure it is more male-dominating because people who teach it are male." While the H5 instructor, however, offered quite a contrary view, as he said, "...There is no male or female mathematics. So is it with business that deals with statistics and modeling. But I don't deny that in some aspects of business education, such as human relations, etc., the difference [between male and female] may exist." Essentially, both of the instructors believed that their classes were fairly gender neutral. The H5 instructor mentioned the notion of "keystone". He used it as an analogy for his belief in a gender-balanced environment. He expressed that he was consciously trying to maintain a gender-balanced environment in the classroom. However, he insisted that it was up to students, not him, to claim whether such a goal has been achieved or not. The M5 instructor was not completely sure whether his course was gender 
neutral. Like the first instructor, he tried to be conscious not to favor one group over another. The majority of students felt that these two specific courses were very gender neutral.

Another question raised related to the gender stereotype; in particular the difference in a male mode of behavior versus that of a female. The responses from both instructors confirmed the existence of such a stereotype. The H5 instructor put it this way, "...When female students exhibit male behaviors, they got rated down...They are called "pushy" by male as well as other female students." The male behaviors might consist of being annoyingly aggressive and persistent. The M5 instructor described the stereotype in a similar manner, "...As in the past, it has been pointed out that for a female to succeed, she would have to act like a male and adopt a male mode of thinking." Interestingly, the female students did not share these perceptions of the gender stereotype. One student described, "I don't know. I am just myself." Another one expressed, “...For me, I was never brought up in a tradition where male and female roles are defined as such how a woman should be and how a man should be." Unanimously, all of the female students responded that they were not aware of the difference in a male mode of behavior versus that of a female. However, such a claim, they elaborated, is only true in school; not in the work place.

\section{Impacts of Online Learning Environment}

One of the unique features in both H5 and M5 classes was the extensive use of IT, especially the group support application. A motivating question for this study was whether such a technology would bring more gender classroom equity to the classes or whether it would create even more barriers for female students? This was a very complex but insightful issue to explore. Based on limited data and observations, the researchers determined that the impact of technology on gender classroom equity could go either way. In some cases, it might be an enabler for more equity but in other cases, it might be a hindrance. The following experiences from the three female students demonstrated this finding.

\section{Negative impact of a CSCL environment as experienced by one student}

In a face-to-face classroom, this student, fictitiously referred to as MA, was observed to be very active. She participated as much as others. She was talkative. Yet, in an online environment, MA transformed into a different person, as she described herself, "I think I become more passive online." As we asked her further, she confided, "What I disliked about the online was that others could not really react to what I was saying..." For instance, she continued, "When I felt that it was an important matter, I repeated it again. But I couldn't get anyone's attention.” For her, the face-to-face environment was much more natural. She said, "You cannot emphasize much online as in a face-to-face. I think I can draw more attention from a group meeting in a face-to-face mode because the way I speak, the words that I put feeling into, the gestures I make, the emotion I feel, etc." Her experience in a CSCL environment was less positive, as she expressed, "In an online, I cannot get much attention. This is one reason why I participate less online."

In a CSCL environment, MA didn't have a feeling of being included and connected. She had not found a way to have a relationship with the class when it was online. She felt more connected when she was in a traditional classroom setting. For her, the use of technology for interacting online seemed to create a wall between her and others. She elaborated:

"...I felt more like a spectator online and not able to make a connection. One good example is the time when I and June facilitated an online discussion in class. We had to prepare a session on shared leadership. We had a simulation that we did in class. Then we wanted to have an online discussion to debrief the simulation. I was facilitating the discussion with June who was at another room at the Sociology department. I was over 
here.... I planned out in advance. I had a set of questions that we could post. I could not keep track of everything being said and meanwhile participating, summarizing, and leading the discussion to the next point. For me, everything was just going from left to right all the time. Because of the different orders that answers were coming, I could not manage."

MA relied on visual, as well as verbal cues in relating to the class. In the absence of these visual cues she did not feel connected to the class. MA was not able to adapt herself in a CSCL environment at all. This was quite clear in her expression below:

"When I had an in-class discussion, I had no problem at all to summarize and guide the discussion. But online, I felt really frustrated. After the online meeting, everyone came together and said, "It was fun and was a great session." I didn't feel this at all. I think this is a good example where I felt disconnected and stumbling and did not do a good job at all."

\section{Positive impacts of CSCL environment as observed and reported by other students}

The case of LH was a contrast to that of MA. In a face-to-face setting, LH was quiet and passive. She rarely spoke up. Yet, in a CSCL environment, a transformation occurred in LH. Here was an example from an online transcript.

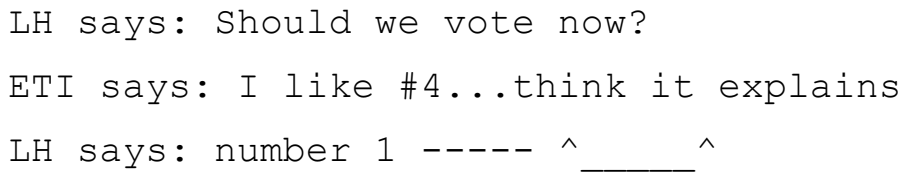

In the excerpt above, she took an initiative to engage the group into voting for the consensus. Then, she drew an icon to make a facial expression. This was quite creative of her. Yet, this initiative would not have happened if the case discussion was only in a face-to-face setting. In this case, the technology opened up the classroom and allowed LH to participate equally. In effect, it helped transform the actions of LH. Another example of the positive impact experienced by LH, came from the comparison of statements made by various students. Based on the record of the transcripts and the tabulation of statements shown in Table 1, LH (shown in italics) was as active as any other students. With $9.12 \%$ of total contribution, she participated and contributed above the class average.

LH is not an isolated case because a similar effect also occurred to AV, one of the students in H5 class. AV came from Mexico. Like LH, she disliked speaking up in class and was never comfortable presenting in front of the group. As expected, she remained quiet in most of the class meetings. When she joined the online case discussions, at first, she was very reserved and overly cautious. AV said, "Language is the barrier. It won't come out in speaking. Then, it won't come out in my writing either..." Hence, she made sure every statement that she wrote was in proper English and made sense. However, the online discussions were in a fast lane. She experienced this fast-moving discussion as she put it, “...When I finally made a point, these guys already were ahead of me with so many comments. So, I could not catch up reading and try to put my thought together." Yet, at the end, she described, "I find that the question [in the online case discussion] is good. I like the structure in the online discussion...". She became comfortable interacting with others online. She found out that she had to let go all the precautions and fear of evaluation. In the end, AV had learned ways to enable her to overcome these constraints and take advantage of the capabilities available in a CSCL environment, so she could positively contribute to the case discussions. 


\section{Participation Levels}

The statistics in Table 1 were from two online case discussions in the M5 class. The level of participation is indicated in terms of comments, remarks, ideas, or statements made by each student during the discussions. The data shows the total number of statements contributed by each student associated with his/her gender.

Table 1: Tabulation of the Number Statements Contributed by Each Student from the Transcripts of Two M5 Online Case Discussion*

\begin{tabular}{|c||c|c||c|c||c|c|}
\hline $\begin{array}{c}\text { Female/Male } \\
\text { Gender }\end{array}$ & Case 1 & $\%$ & Case 2 & $\%$ & Total & $\%$ \\
\hline F-LH & 10 & 8.93 & 15 & 9.38 & 25 & 9.12 \\
\hline F-Learner2 & 10 & 8.93 & 23 & 14.38 & 33 & 12.04 \\
\hline F-Learner3 & 13 & 11.61 & 11 & 6.88 & 24 & 8.76 \\
\hline F-Mean & 11 & 9.82 & 16.33 & 10.21 & $\mathbf{2 7 . 3 3}$ & 9.97 \\
\hline M-Learner4 & 12 & 10.71 & 18 & 11.25 & 30 & 10.95 \\
\hline M-Learner5 & 10 & 8.93 & 4 & 2.50 & 14 & 5.11 \\
\hline M-Learner6 & 12 & 10.71 & 1 & 0.63 & 13 & 4.74 \\
\hline M-Learner7 & 13 & 11.61 & 4 & 2.50 & 17 & 6.20 \\
\hline M-Learner8 & 11 & 9.82 & 18 & 11.25 & 29 & 10.58 \\
\hline M-Learner9 & 12 & 10.71 & 19 & 11.88 & 31 & 11.31 \\
\hline M-Mean & 11.67 & $\mathbf{1 0 . 4 1}$ & 10.67 & $\mathbf{6 . 6 7}$ & $\mathbf{2 2 . 3 3}$ & $\mathbf{8 . 1 5}$ \\
\hline Total Mean & 11.44 & $\mathbf{1 0 . 2 2}$ & $\mathbf{1 2 . 5 5}$ & $\mathbf{7 . 8 5}$ & $\mathbf{2 4}$ & $\mathbf{8 . 7 6}$ \\
\hline Totals & $\mathbf{1 0 3}$ & $\mathbf{9 1 . 9 0}$ & $\mathbf{1 1 3}$ & $\mathbf{7 0 . 6 5}$ & $\mathbf{2 1 6}$ & $\mathbf{7 8 . 8 1}$ \\
\hline
\end{tabular}

* Instructor's contribution is not included here

Most of the M5 online sessions consisted of students who were either anonymous or identified by nicknames; therefore, it was not possible to trace the gender associated with each statement. Only two sessions in M5 were included in this tabulation because the students' gender was traced back from the associated usernames or nicknames. Students were split into two groups based on gender (F: Female; M: Male), then compared to the total contribution of statements for each group. The statistical test - Mann-Whitney U - was applied since it can be used for the comparison of two independent samples in non-parametric statistics, especially when the larger sample is 20 or less. The comparison between two groups male and female resulted in a t-value of 1.11 at a 0.05 significance level. Generally, a 0.05 significance level would be considered significant. However, given the sample size and the exploratory nature of this study, the researchers did not feel that this was strong enough evidence to demonstrate that a statistically significant difference existed in the total number of statements contributed by each gender. A simple tabulation on the number of statements contributed by each learner is shown in Figure 2. Based on the average, it appears that there is no significant difference in the number of statements contributed by male and female students. 


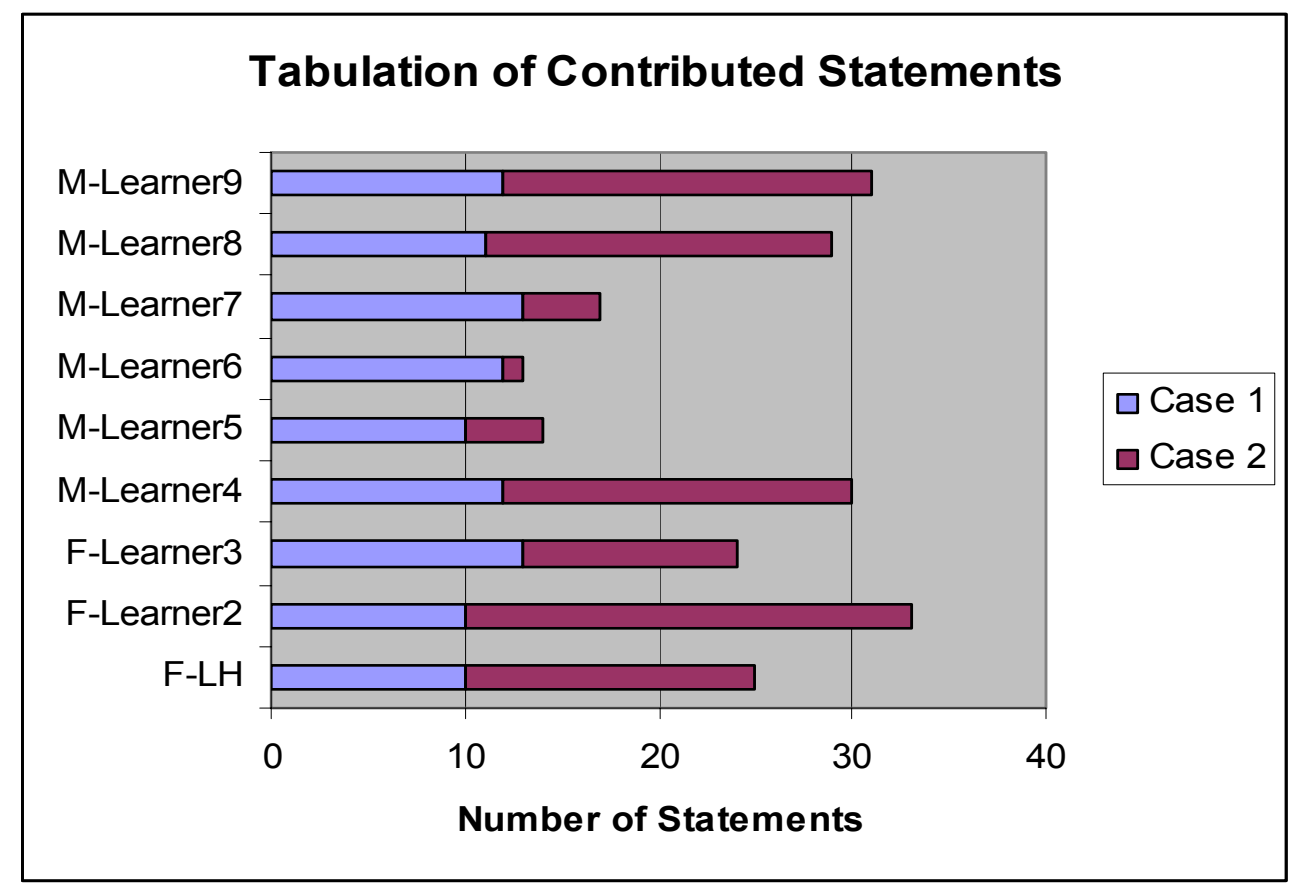

* Learner Identified by the Gender: F-Female and M-Male

Figure 2: Tabulation on the Number of Statements Contributed by Each Learner in Two Online Sessions

\section{Discussion}

One interesting observation from the field study is that the experiences of the three female students provide two seemingly contradictory outcomes with respect to the impact of the technology on gender classroom equity. This observation again suggests that the impact of technology might be experienced differently by different users although the same technology is being deployed. The implication here is that the impact of technology can be both positive and negative. It might create potential barriers for some female students. At the same time, it might open up the classroom for others. If it is carefully implemented and properly used, as just one of several methodologies used in a course, this technology has the potential to bring gender equity to the classroom. CSCL features promote equal participation and active involvement for all students which can help shy and passive students of either gender reach his/her highest potential in the course. The technology can be an effective mechanism to foster the enrichment of classroom choices and opportunity as well as to support the empowerment for all students to overcome constraints and barriers in their learning environment.

Traditionally, learning outcomes are often measured in terms of test scores, student performance, mastery of content, satisfaction, achievement, students' perceptions of their learning, and so on. They are all based on instrumental purposes because they are oriented toward objective knowledge and well-defined guidelines. However, in our adaptation of Habermas's Theory of Cognitive Interests, we argued earlier that instrumental purpose should not be the only basis for assessing learning outcome. Instead, we recognized other potential learning outcomes that may derive from group negotiation, sense-making, shared understanding, positive socialization, conflict, critical reflection, and personal growth and development. These aspects of learning outcomes characterize what we proposed to describe as communicatively and emancipatory-oriented learning. 
It was observed that given the autonomy in an online environment, students assumed more responsibility in their learning by engaging more actively in the facilitation of the discussion process and carrying greater voices in the course of the discussion. This is evidence for the instrumental purpose of technology implementation. With the use of technology, students were able to learn in their own pace and become more proactive in their interactions with one another. Our observation showed that the use of TeamWave in the study helped to create a powerful and flexible learning environment. For instance, with the capability of parallel communication, every student could participate at any time. There was no need to wait for airtime in an online discussion. There was less chance of a few individuals dominating the discussion. In this case, the drive for achieving efficiency and effectiveness is instrumentally motivated. A CSCL environment provides a forum in which students were encouraged to participate and become active. The process became much more efficient and effective than in the case of face-to-face interaction.

In a traditional classroom, learning objectives often focus on helping students to develop the ability to understand concepts, to analyze problems, to synthesize solutions, and to make decisions. Since past studies have extensively looked at these learning outcomes, our study explored other subtler aspects in group learning processes. Observations and the focus group transcripts, suggested that learning also occurred when students engaged in group negotiation, sense-making, shared understanding, positive socialization, conflict, critical reflection, and personal growth and development. These learning outcomes were not content-oriented but process-oriented. For instance, despite the lack of cues and gestures, students learned to make themselves understood by others through text-based discussion. They interacted with one another to achieve shared understanding, to resolve conflicting views, and to overcome barriers or constraints. Our study showed that the use of technology enhanced and fostered the group's striving for shared understanding and consensus building. These are indicators of communicatively oriented learning. These results are consistent with the communicative dimension of learning that concerns the way students make themselves understood by others through speech, writing, and communication in a sensemaking process (Bullough \& Goldstein, 1984; Carr \& Kemmis, 1986; Hoffman, 1987; Mezirow, 1981).

Most abstract is perhaps the emancipatory orientation, which concerns itself with the human's interest to overcome both external and internal constraints in order to reach his/her full potential. External constraints in this context are forces that are often associated with institutional policy and regulation, whereas internal constraints refer to the internal compulsion that hinder an individual as a result of misconceptions or biased ideologies (Carr \& Kemmis, 1986; Mezirow, 1981). The key element in emancipatory learning is an individual's capacity to achieve freedom from self-imposed constraints, reified social forces and institutions, and conditions of distorted communication (Roderick, 1986, p. 56). LH's case is perhaps one of the more subtle indicators of "emancipatory-oriented learning" as described in the earlier section. In class, LH rarely spoke up. Yet, when the case discussion went online, she was anything but shy. She contributed as many comments and ideas as others. She was not afraid to take initiatives such as asking others to vote and drawing a smiling face. It would be difficult to detect such transformation from the test scores alone. This kind of learning is manifested in students' action to be self-determining and self-reflective. The case of LH showed an instance of learning through the transformation taken place in the student's attitude, belief, and action. By overcoming her own constraints, she was able to participate in the discussion without the feeling of being coerced or any judgmental reservation. Despite various interpretations of emancipatory-oriented learning, its essence rests on the fundamental premise that humans in principle are willing and able to overcome barriers in order to achieve their potential. Emancipatory-oriented learning is especially empowering for female students who have to deal with gender stereotypes and inequity in the classroom. 
The examples above highlight some of the non-traditional learning outcomes that we discovered to be quite relevant to the nature of communicative and emancipatory learning. As discussed, examining the communicatively and emancipatory-oriented learning shows that computer-mediated environments can provide an effective forum for immediate, multi-party communication among group members and sometimes with minimum clues to a participant's gender identity. As a result, when interpreting the impact of technology from a gender classroom equity perspective, the results suggest computer conferences as likely to facilitate full female participation. All of these interpretations are consistent with past studies related to the positive effects of computermediated environment. Findings from studies such as Harasim (1987) and McConnell (1988, 1997) suggest that computer conferences allow for more participatory dynamics than face-to-face meetings. From a broader perspective, enthusiasts of CSCL and other computer-mediated communications advocate this as a democratizing force, because of the immediate accessibility each participant has to the myriad others. Some researchers claim the use of the electronic medium can afford a more democratic process than face-to-face meetings for peer discussions, since each individual can have an equal opportunity to take part in online conversations without the many constraints of face-to-face settings (see, for example, Harasim, 1987 and McConnell, 1988, 1997).

A few decades ago, the computer was observed to be male dominated. Its usage belonged to the techies comprised mostly of men. With the growth of computer usage in recent years, this male domination was not only sustained but also expanded. As a result, it is not surprising to see the outcomes of past studies (Brooks, 1982; Eakins \& Eakins, 1978; Hardy, Hodgson, McConnell, \& Reynolds, 1991) indicating that female participants perceive male participants as dominating conversations in an online environment. Male domination was demonstrated through evidence, such as males taking more of the available time per turn, talking longer, and speaking more often than females in a computer-mediated environment. However, the findings in Table 1 and Figure 2 suggest a reversal in this trend. There was no statistically significance validating gender differences in the pattern of online interactions between male and female students in this study. The pattern is particularly interesting because the most active student (F-Learner2) defined by the number of idea contributions turned out to be female (see Figure 2). Using simple tabulation of the number of statements contributed by each learner in the two online sessions, on average, the female students were also as involved as their male counterparts. While there are many contributing factors, one possible explanation is the emergence of the less male dominated conversation in these observations. The decline of male domination could be attributed to the significant growth of female Internet users. According to Market Facts, Inc., a third of women and nearly four in ten men have used online services or the World Wide Web. Most often female online users are spending their time communicating through E-mail (31\%) ("Women Use Online Time," 1998, p. 14.). With the Internet becoming ubiquitous and more female users joining, male domination of conversations might not be as significant. Recent studies show that in the U.S.A. and Canada the number of female Internet users exceeds the number of males users, however the width, functional depth and overall depth of adoption either tends to be higher for men or is dependent on the application (Dholakia, Dholakia, \& Kshetri, 2003). One of the greatest strengths of the modern communication medium such as e-mail is its ability to break down socio-economic, racial, and other barriers in communication and hence improve information exchange for the purpose of understanding and learning rather dominating the interactions (Hank, 1995, p.1).

\section{Pedagogical Implications}

The primary reason for pursuing this line of research is to ensure that CSCL is adding value to the classroom. Does it help improve the effectiveness and efficiency of classroom discussions which ultimately should improve student learning? Then CSCL is worth the investment of institutional and instructors' resources and time. This study looked at the impact the use of CSCL has on female students. Given the scope of the project and the perception that computer technology is male 
dominated, we felt that using female students as the subjects would provide the most knowledge and significant results.

Instructors and students are challenged to foster and manage an online learning environment that provides gender classroom equity. This is a complex process because classroom dynamics often evolve and are unpredictable. In addition to maintaining control of the group interaction, engaging students to participate from different locations, and manipulating the technology with limited socio-emotional cues, the instructor needs to be supportive of communicative-oriented, and more importantly, emancipatory-oriented learning. To cultivate gender classroom equity and encompass both communicative and emancipatory learning, this focus group study suggests the following pedagogical implications for teaching an effective gender-neutral online class:

1. When class demographics include both genders, instructors need to assess class discussions to ensure equal participation by all the students. If participation is not equal, then alternative class discussion methodologies (i.e. use of online discussions along with in class discussions) need to be offered to make sure all students in the class will have a chance to participate. By doing so, the instructors can empower students especially the female students, to be active learners.

2. Instructors need to be sensitive about student differences and may need to experiment with various instructional methodologies to stimulate student involvement in the course.

3. Students have different prior experiences with technology. If technology will be used as part of the course then to guarantee that all students in the class have the same level of expertise, additional training may be needed.

4. Use of a variety of CSCL features is important. It is recommended that females have a greater involvement in designing and assessing various features of CSCL. This will help to ensure that CSCL facilitates the learning process of female and male students.

\section{Limitations of the Study}

Like any exploratory study using qualitative methods, this study does have some inherent limitations. First of all is the subjective nature in this study. As participant observers of the learning process, the authors' views were inevitably influenced by preconceived ideas and available resources. For instance, the selection of these subjects might be seen as biased. A second limitation is the sample size. However, it is difficult to have large sample sizes when using a focus group without tainting the results of the study.

\section{Future Research}

This study could be methodologically strengthened by including focus group interviews with male students in addition to the perspectives from female instructors. Since the sample of subjects participating in the study might not be representative, any generalized implications should be taken with caution. Another limitation is related to the learning environment. The setting of this study was unique; hence, the results might be difficult to duplicate in other situations. Each class has a unique make up of student personalities and demographics, along with instructors who incorporate previous course experiences into new classes, thereby creating courses that have their own characteristics and are distinct when compared to other courses. However, it will be helpful to gather information from additional courses to help instructors better understand how and when to use CSCL. Future research could also look at other demographic variables such as age, computer literacy, and ethnic groups to determine if CSCL is an effective and efficient tool to enhance classroom discussion and participation or if it adds an additional expense and complexity to the classroom without adding benefits. 


\section{Conclusion}

This study represents one of the few early efforts to fill the need for research lag behind the increasing use of CSCL in practice as pointed out by Alavi and Leidner (2001). This study was undertaken to explore the CSCL integrated into the learning processes in a natural classroom setting. The study examined the use of the CSCL from a participant observer's perspective. The use of the focus group method allowed direct contact with the subjects. Hence, by virtue of being involved in and close to the phenomenon, subtle aspects on gender equity issues were detected from the use of the CSCL. Although there are many quantitative and cross-sectional studies related to CSCL, few studies have been done to investigate the aspects of gender issues and learning in an online environment. In this respect, this study is both timely and significant. This is one of the earliest attempts to better understand what female students go through and experience in a group learning process in an online environment.

To establish a theoretical base, Habermas' Theory of Cognitive Interests was selected to guide our data collection and interpretation. The study is among the first empirical research that applies and extends the view of e-learning productivity from the perspective of Habermas' Cognitive Interests Theory (Huynh, 2005). Although evidence of emancipatory learning was not easily observed, this study pointed out a few instances (e.g. LH's case) as indicators of the subtle transformation facilitated and supported by a CSCL environment. Furthermore, this study addresses the practical implications of implementing multiple methodologies for class discussions through the use of CSCL.

Finally, there is a need to step back and reflect on current practices and learned experiences so that the appropriate technology can be integrated into learning and teaching environments; to achieve not only the instrumental but also the communicative and emancipatory aspects of the learning process. The ease of capturing everything online with the technology for reexamination and reflection opens up new possibility for educators to broaden the objectives of teaching and research. Such objectives could include knowledge acquisition and transfer, as well as knowledge construction, meaning negotiation, questioning shared values, and challenging taken-for-granted assumptions. All of these aspects are critical in today's learning process, especially with the integration of computer supported technologies - CSCL - into already time and content pressured courses.

\section{Acknowledgements}

We gratefully acknowledge the feedback and comments from Christine Bruce (Editor) and the anonymous reviewers.

\section{References}

Alavi, M. (1994). Computer-mediated collaborative learning: An empirical evaluation. MIS Quarterly, 18 (2), 159-174.

Alavi, M. \& Leidner, D. (2001). Research commentary: Technology-mediated learning: A call for greater depth and breadth of research. Information Systems Research, 12 (1), 1-10.

Alavi, M., Wheeler, B., \& Valacich, J. (1995). Using IT to reengineer business education: An exploratory investigation of collaborative telelearning. MIS Quarterly, 19 (3), 293-312.

Bullough, R. V., \& Goldstein, S. L. (1984). Technical curriculum form and american elementary-school art education. Journal of Curriculum Studies, 16(2), 143-154.

Briggs, R. O., Ramesh, V., Romano, N. C. \& Latimer, J. (1995). The exemplar project: Using group support systems to improve the learning environment. Journal of Educational Technology Systems, 23 (3), 277-291. 
Brooke, C. (2002). Critical perspectives on information systems: An impression of the research landscape. Journal of Information Technology, 17 (4), 271-285.

Brooks, V. R. (1982). Sex differences in student dominance behavior in female and male professors' classrooms. Sex Roles, 8, 683-690.

Carr W., \& Kemmis, S. (1986). Becoming critical—Education, knowledge and action research. Philadelphia: Falmer.

Cranton, P. (1996). Types of group learning. New Directions for Adult and Continuing Education, 71, Fall, 25-32.

Davidson-Shivers, G., Morris, S. \& Sriwongkol, T. (2001). Gender and online discussions: Similarities or differences? World Conference on Educational Multimedia, Hypermedia and Telecommunications, 1, 361-366.

Davidson-Shivers, G., Morris, S. \& Sriwongkol, T. (2003). Gender Differences: Are they diminished in online discussions? International Journal on E-Learning, 2 (1), 29-36.

Dholakia, R. R., Dholakia N. \& Kshetri N (2003). Gender and Internet usage. In H. Bidgoli (Ed.), The Internet Encyclopedia. New York: Wiley.

Eakins, B. \& Eakins, G. (1978). Verbal turn taking and exchanges in faculty dialogue. In: B. L. Dubois \& I. Crouch (Eds.) Papers in Southwest English IV. Proceedings of the Conference on the Sociology of the Languages of American Women, 5362 (San Antonio, TX, Trinity University)

Gilligan, C. (1982). In a different voice: Psychological theory and women's development. Cambridge, Mass: Harvard University Press.

Gunn, C., McSporran, M., Macleod, H., \& French, S. (2003). Dominant or different? Gender issues in computer supported learning. Journal of Asynchronous Learning Networks, 7(1), 14-30.

Habermas, J. (1972). Knowledge and human interests. London: Heinemann.

Hall, R. M. \& Sandler, B. R. (1982). The classroom climate: A chilly one for women? Washington, D.C: Association of American Colleges.

Hank, B. (1995). Gender dynamics online: What's new about the new communication technologies? Feminist Collections: A Quarterly of Women's Studies Resources, 16 (2), 16.

Harasim, L. (1987). Teaching and learning online: Issues in computer mediated graduate courses. Canadian Journal of Educational Communication. 16, 117-135.

Hardy, V., Hodgson, V., McConnell, D, \& Reynolds, M. (1991). Computer-mediated communications for management training and development a research report. Presented at the Women in Management Learning Conference, Centre for the Study of Management Learning, Lancaster University.

Hellens, L. V. Nielsen, S. H, \& Beekhuyzen, J. (2004). An exploration of dualisms in female perceptions of IT work. Journal of Information Technology Education, 3, 103-106.

Hensel, N. (1991). Realizing gender equality in higher education: The need to integrate work/family issues. ASHE/ERIC Higher Education Report No. 2.

Herring, S. (2000). Gender differences in CMC: Findings and implications. The CPSR Newsletter, 18 (1). Retrieved December 5, 2003, from http://www.cpsr.org/publications/newsletters/issues/2000/Winter2000/herring.html.

Herring. S. (2001). Gender and power in online communications. Center for Social Informatics Working Paper. Indiana University-Bloomington. Retrieved May 9, 2005, from http://www.slis.indiana.edu/CSI/WP/WP01-05B.html

Hoffman, M. (1987). Critical theory and the inter-paradigm debate. Journal of International Studies, 16(2), 231-249. 
Huynh, M. (2005). Viewing e-learning productivity from the perspective of Habermas' cognitive interests theory. Journal of Electronic Commerce in Organizations for Review (Special Issue on Social Aspects of E-Business), April-June, 33-45.

Iankelevich, D. (2005). Women online in the US: A growing majority. eMarketer. Retrieved May 7, 2005 from http://www.emarketer.com/report.aspx?women may05

Jones, M. R. (2000). The moving finger: The use of social theory in WG8.2 conference papers, 1975-1999. In R. Baskerville, J. Stage, \& J. I. DeGross (Eds.), Organizational and social perspectives on information technology (pp. 15-31). Dordrecht: Kluwer Academic Publishers.

King, L. (2000). Gender issues in online communities. CPSR Newsletter, 18(1). Retrieved December 5, 2003, from http://www.cpsr.org/publications/newsletter/issues/2000/Winter2000/king.html

Kwok, C. W. R., Ma J., \& Vogel D. (2002). Assessing GSS and content facilitation effect on knowledge acquisition. Journal of Management Information Systems, 19 (3), 185-229.

Larson, P. (2002). Interactivity in an electronically delivered marketing course. Journal of Education for Business, 77 (5), 265-266.

McConnell, D. (1988). Group communications via computer conferences - the educational potential. In D. Smith (Ed.), New technologies and professional communications in education. London: NCET.

McConnell, D. (1997). Interaction patterns of mixed sex groups in educational computer conferences. Part I-Empirical Finding. Gender and Education, 9 (3), 345-363.

Mezirow, J. (1981). A critical theory of adult learning and education. Adult Education, 32 (1), 3-24.

Mingers, J. \& Willcocks, L. (2004). Social theory and philosophy for information systems. London, England: John Wiley and Sons.

Ono, H. (2002). Gender and the Internet - Statistical data included. Federal Reserve Bank of Atlanta Working Paper Series. Retrieved May 7, 2005, from http://www.findarticles.com/p/articles/mi_m0KXF/is_2002_June_24/ai_90305995/print

Pearson, J. C., West, R. L. \& Turner, L. H. (1994). Gender and communication (3rd ed.). Dubuque, IA: Wm. C. Brown. \& Benchmark.

Roderick, R. (1986). Habermas and the foundations of critical theory. St. Martin's, New York.

Shimanoff, S. \& Jenkins, M. (1994). Leadership and gender: Challenging assumptions and recognizing resources. In R. S. Cathcart and L. Samovar (Eds.). Small group communication: A reader. Dubuque, IA: Wm. C. Brown.

Wang, M, \& Sierra, C. (2002). Gender, discourse style, and equal participation in online learning. World Conference on E-Learning in Corp., Govt., Health, \& Higher Ed. (1), 2364-2367.

Wilson, M. (2004). A conceptual framework for studying gender in information systems research. Journal of Information Technology (Pelgrave Macmillian), 19(1): 81-93. Retrieved September 17, 2004 from http://www.pelgrave-journals.com

Women use online time for communicating, researching. (1998). About Women \& Marketing, 11 (9), 14.

Wyatt, N. (1993). Organizing and relating: Feminist critique of small group communication. In N. Wyatt and S. P. Brown (Eds.), Transforming visions: Feminist critiques in communication studies (pp. 5186). Cresskill, N.J.: Hamplton Press.

Young, S. \& McSporran, M. (2001). Confident men - successful women: Gender differences in online learning. World Conference on Educational Multimedia, Hypermedia, and Telecommunications, (1), 2110-2112. 


\section{Biographies}

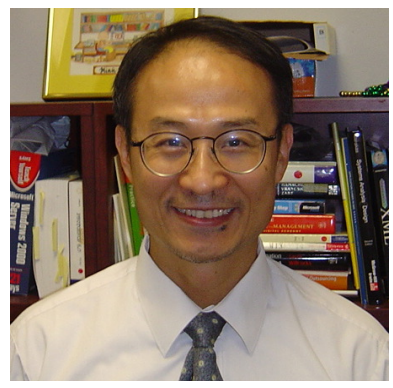

Minh Q. Huynh is an Assistant Professor at Southeastern Louisiana University. He received his Ph.D. from State University of New York at Binghamton. His teaching expertise is in the areas of E-commerce, Telecommunications, and Decision Support Systems. Research interests include E-learning, computer supported collaborative learning, IS outsourcing, application of Habermas' Critical Social Theory in IS research. His publications appear in such journals as the Communications of ACM, Journal of AIS, Communications of AIS, European Journal of IS, and Journal of Electronic Commerce in Organizations. Prior to his academic career, he had worked in the areas related to computer programming, systems management, technical support, and network security.

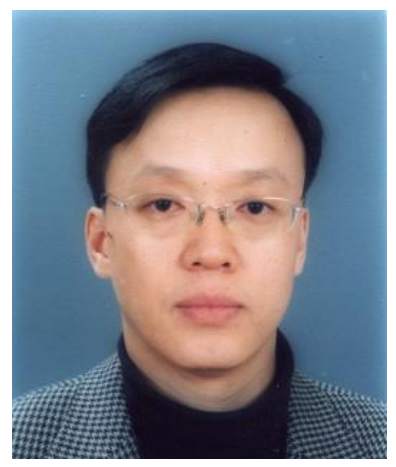

Jae-Nam Lee is currently an Assistant Professor in the School of Business IT at Kookmin University in Seoul, Korea. Previously, he taught at the City University of Hong Kong for four years. He holds M.S. and Ph.D. degrees in MIS from the Graduate School of Management of the Korea Advanced Institute of Science and Technology (KAIST) in Seoul. His research interests are IT Outsourcing, Knowledge Management, e-Commerce, and Computer Supported Collaborative Learning. His published research articles appear in MIS Quarterly, Information Systems Research, Journal of MIS, Journal of the AIS, IEEE Transactions on Engineering Management, European Journal of Information Systems, Communications of the ACM, Information \& Management, and others. He has also presented several papers at the ICIS, HICSS, ECIS, DSI and IRMA Conferences.

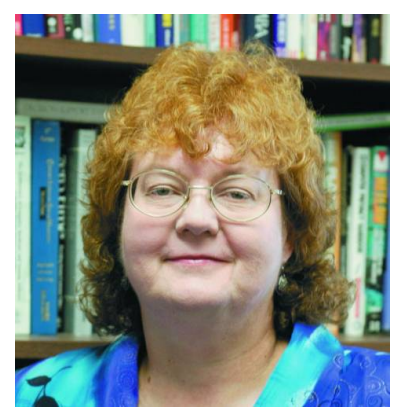

Barbara A. Schuldt, $\mathrm{PhD}, \mathrm{CCP}$ is an associate professor in the management department at Southeastern Louisiana University. Her research focus has been on ethical use of information systems and technology, data capture via technology and the teaching management information systems. She is active in Information Resource Management Association and reviews for Information Resource Management Journal, Journal of Database Management, and Decision Sciences Institute. 